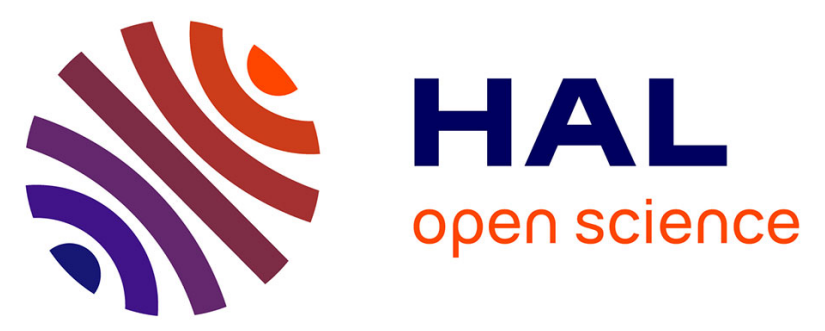

\title{
Are falls in people with multiple sclerosis related to the severity of urinary disorders?
}

Claire Hentzen, Anaïs Villaumé, Nicolas Turmel, Camille Chesnel, Frédérique Le Breton, Rebecca Haddad, Gérard Amarenco

\section{- To cite this version:}

Claire Hentzen, Anaïs Villaumé, Nicolas Turmel, Camille Chesnel, Frédérique Le Breton, et al.. Are falls in people with multiple sclerosis related to the severity of urinary disorders?. Annals of Physical and Rehabilitation Medicine, 2021, 64 (4), pp.101452. 10.1016/j.rehab.2020.10.006 . hal-03365392

\section{HAL Id: hal-03365392 \\ https://hal.sorbonne-universite.fr/hal-03365392}

Submitted on 5 Oct 2021

HAL is a multi-disciplinary open access archive for the deposit and dissemination of scientific research documents, whether they are published or not. The documents may come from teaching and research institutions in France or abroad, or from public or private research centers.
L'archive ouverte pluridisciplinaire HAL, est destinée au dépôt et à la diffusion de documents scientifiques de niveau recherche, publiés ou non, émanant des établissements d'enseignement et de recherche français ou étrangers, des laboratoires publics ou privés. 


\title{
Are falls in people with multiple sclerosis related to the severity of urinary disorders?
}

Claire Hentzen $\mathrm{MD}^{1}$; Anaïs Villaumé ${ }^{1}$ Nicolas Turmel, $\mathrm{MD}^{1}$; Camille Chesnel, $\mathrm{MD}^{1}$; Frédérique Le Breton, $\mathrm{MD}^{1}$; Rebecca Haddad, $\mathrm{MD}^{1}$; Gérard Amarenco, $\mathrm{PhD}^{1}$

${ }^{1}$ Sorbonne Université, GRC 001, GREEN Groupe de Recherche Clinique en Neuro-Urologie, AP-HP, Hôpital Tenon, F-75020 Paris, France

\begin{abstract}
Background. Lower urinary tract symptoms (LUTSs), especially overactive bladder, are frequent in people with multiple sclerosis (PwMS). Urinary urgency and urge urinary incontinence could lead to precipitation and thus could increase the risk of falling in these individuals.
\end{abstract}

Objective. We aimed to assess the association between severity of LUTSs and risk of falling in PwMS.

Methods. PwMS with LUTSs were recruited in a neuro-urology department. Participants were asked about the number of falls in the past 3 months and their circumstances. Severity of LUTSs was assessed by the Urinary Symptoms Profile (USP) score, and individuals were classified as with or without urinary incontinence.

Results. This cross-sectional study included 154 patients (69\% women); the mean (SD) age was 50.1 (11.5) years and median EDSS was 5 (IQR [3-6]). Overall, 20 (13\%) patients reported one fall during the past 3 months, and 43 (28\%) reported at least 2 falls. Only 9 (6\%) patients reported a fall on the way to the toilet, 6 during a urinary urgency. No link was found between falls and urinary incontinence $(\mathrm{p}=0.71)$, type or severity of urinary symptoms (overactivity, voiding dysfunction or stress incontinence, $\mathrm{p}>0.05$ ). Falls on the way to the bathroom was associated with high USP score related to overactive bladder $(\mathrm{p}=0.03)$ and severe nocturia $(>2$ 
nocturnal micturitions $)(\mathrm{p}<0.01)$. Falling at night was also associated with severe nocturia $(\mathrm{p}<$ $0.001)$.

Conclusions. The severity of LUTSs and presence of urinary incontinence do not appear related to the risk of falling in PwMS and urinary disorders but rather to the specific risk of falling on the way to the bathroom. Severe nocturia increases the risk of falling at night. Further studies are needed to assess the impact of LUTS treatment on the risk of falling.

ClinicalTrials.gov (NCT04338646)

Keywords: fall, multiple sclerosis, lower urinary tract symptoms, overactive bladder

\section{Introduction}

Falls are a common problem in people with multiple sclerosis (PwMS) and can lead to severe consequences (trauma, fear of falling, reduction of social activities). Prevention of falls is one of the priority targets of rehabilitation for PwMS and walking difficulties, which can result from different factors (motor impairment, ataxia, visual alterations, sensitive disorders, fatigability etc.). Some clinical characteristics related to motor impairment (gait velocity, 12-Item Multiple Sclerosis Walking Scale [MSWS12] score)[1] or fear of falling (Falls Efficacy ScaleInternational [FES-I] score)[2] have been identified as risk factors of falling. Urinary incontinence has also been considered to predict falls, initially in older adults[3,4] but secondary in PwMS[5-7].

However, lower urinary tract symptoms (LUTSs) are frequent in PwMS, with a high prevalence (32-96.8\%) and an increase with MS duration and severity of neurological deficiencies and disabilities[8]. Overactive bladder with urgency, frequency, urge urinary incontinence and nocturia is the most common symptom, reported by $37 \%$ to $99 \%$ of PwMS. Overactive bladder 
affects quality of life, and a neurogenic bladder with detrusor overactivity associated with detrusor sphincter dyssynergia on urodynamic assessment can lead to an altered upper urinary tract (reflux, dilatation, urinary tract infection)[9-13]. Despite its high prevalence and impact on quality of life, the severity of LUTSs has never been studied as specific risk factor of falling. However, urinary urgency and urinary incontinence could lead to precipitation and thus could increase the risk of falling in these patients. This hypothesis had been previously evoked in older adults[14,15].

The primary aim of the study was to assess the association between severity of LUTSs and risk of falling in PwMS. The secondary aim was to correlate patient characteristics and clinical tests with risk of falling. The study was conducted and results were reported according to the STROBE guidelines for cross-sectional studies (see additional material).

\section{Material and methods}

Study design

This study was approved by the local ethics review board (RCB: 2018-A01644-51) and all participants provided written informed consent before inclusion in this cross-sectional study. This study was registered at ClinicalTrials.gov (NCT04338646). Participants were recruited in a neuro-urology department during a medical appointment or a urodynamic assessment or in a day hospital related to urinary disorders between July 2019 and January 2020.

\section{Participants}

Inclusion criteria were age $\geq 18$ years with an MS diagnosis, LUTSs with or without treatment, and Expanded Disability Status Scale (EDSS) score 1 to 6.5. Exclusion criteria were relapse of MS in the past month, urinary tract infection on the day of inclusion, and inability to complete the symptom questionnaires. 


\section{Procedure}

Collected data were age, sex, EDSS score, body mass index, need for visual correction and use of a walking aid. Patients were asked about the number of falls in the past 3 months and in the past year and the circumstances in which they occurred (frequency, home, outdoors, going to void, during urinary urgency, nocturia). Number of falls was classified as 0,1 or at least 2 to quantify the severity of risk of falling. A better precision was not possible owing to the retrospective collection and would have led to classification bias. Severity of LUTSs was assessed by the Urinary Symptoms Profile (USP) score[16] and participants were classified as with or without urinary incontinence. Number of micturitions at night was specifically asked. To take into account motor difficulties and fear of falling, other clinical evaluations were done. The impact of MS on walking was assessed with the MSWS12 questionnaire [17], the EDSS score, and a clinical test with the Time to be Ready to Void (TRV) test [18]. Fear of falling was assessed by a simple question and with the FES-I questionnaire[19].

The primary aim was to assess the association between severity of LUTSs and occurrence of falls during the past 3 months. The primary outcome was the importance of overactive bladder (OAB) symptoms with the OAB USP score. Secondary outcomes were the existence of urinary incontinence, the warning time (defined as the time from the first sensation of urgency to voiding or incontinence), the importance of nocturia and the other sub-scores of the USP questionnaire (voiding dysfunction and stress urinary incontinence).

Secondary aims were to look for the relationship between severity of LUTSs and specific circumstances of falls, severity of LUTS and occurrence of falls during the past year, and to assess the association between falls and classical risk factors of falls. 


\section{Statistical analysis}

Because the frequency of falls in PwMS is variable in literature (30-63\%[20]), and there are no data on the impact of the severity of urinary disorders on the risk of falling, the number of participants to be included could not be calculated. The minimal target of inclusion was 100 participants by estimating the reported fall rate at about $30 \%$, which allowed us to use parametric tests on the primary outcome. The number of missing data was very low, so these were not replaced. Statistical analyses involved using $\mathrm{R}$ for Windows (Rx64 3.4.2, R Foundation for Statistical Computing, Vienna, Austria). Descriptive data are presented as number $(\%)$ or mean (SD) for continuous data and median (range) for ordinal data and data not normally distributed. The impact of the different factors on the risk of falling was assessed by Student $t$ test and ANOVA for quantitative variables if normally distributed or Welch's t-test otherwise, and chi-square test or Fisher exact test for categorical variables. Statistical significance was set at $\mathrm{p}<0.05$. A logistic regression model was applied to search for risk factors in multivariate analysis.

\section{Results}

\section{Patient characteristics}

In total, 509 PwMS were seen in the department during the inclusion period; 167 did not meet the inclusion criteria and 188 declined participation. We included 154 patients (69\% women; Figure), with mean (SD) age 50.1 (11.5) years and median EDSS 5 (range 3-6). All participants completed the full study. The demographic characteristics of participants are reported in Table 1. Over the past 3 months, $13 \%(n=20)$ of PwMS reported 1 fall and $28 \%(n=43)$ reported at least 2 falls; $25 \%$ reported falls indoors and 30\% outdoors (Table 2). Over the past year, 10\% reported 1 fall and $45 \%$ reported at least 2 falls; $36 \%$ reported falls indoors and $43 \%$ outdoors. 
Association between reported falls and LUTSs

We found no link between the reported falls during the past 3 months and severity of LUTSs (USP sub-scores: OAB, voiding dysfunction or stress incontinence, $\mathrm{p}>0.05$ ) or urinary incontinence $(\mathrm{p}=0.71)$. Falling at night was associated with severe nocturia $(>2$ nocturnal micturitions) $(\mathrm{p}<0.001)$ but not with overall risk of falling (including falls during the day and at night). Similar results were found between the reported falls during the past year and severity of LUTSs. Results are summarized in Table 3.

Association between reported falls on the way to the bathroom and LUTSS

Over the past 3 months, $9(6 \%)$ patients reported a fall on the way to the bathroom, 6 of them during a urinary urgency. These 9 patients had higher mean (SD) OAB USP score than others (9.9 [5.8] vs 6.5 [4.7], $\mathrm{p}=0.03)$ and $56 \%(\mathrm{n}=5)$ had severe nocturia (vs $16 \%$ for the rest of the participants, $\mathrm{p}<0.01)$. We found no difference concerning urinary incontinence or use of selfcatheterization.

Over the past year, $11(7 \%)$ patients reported at least one fall on the way to the bathroom, 7 of them during a urinary urgency, which represent $13 \%$ of participants who had ever fallen. Again, participants who reported fall on the way to the bathroom had higher mean OAB USP score than others $(11.3$ [3.8] vs 6.5 [4.7], p < 0.01) and a higher proportion had severe nocturia $(45 \%$ vs $17 \%, \mathrm{p}=0.04)$.

\section{Association between reported falls and motor symptoms or fear of falling}

On univariate analysis, factors associated with increased risk of falling during the past 3 months were EDSS score $(p<0.001)$, fear of falling and FES-I score $(p<0.001)$, MSWS12 score $(\mathrm{p}<0.0001)$, use of a walking device $(\mathrm{p}=0.02)$, gait velocity (mobility stage of TRV) $(\mathrm{p}<0.01)$, 
settled stage of TRV $(\mathrm{p}<0.0001)$, and total TRV score $(\mathrm{p}<0.001)$. The same factors were significantly associated with the risk of fall during the past year.

On multivariate analysis, falls in the past 3 months was associated with MSWS12 score (odds ratio $[\mathrm{OR}] 1.04$ [95\% confidence interval $(\mathrm{CI}) 1.01-1.06], \mathrm{p}<0.001)$ and total TRV score $(1.03$ $[1.0-1.06], p=0.03)$ (Table 4). Falls in the past year was associated with fear of falling (3.15 [1.15-8.31], $\mathrm{p}=0.03)$ and MSWS12 score $(1.03$ [1.01-1.05], $\mathrm{p}<0.01)$.

\section{Discussion}

Among the 154 PwMS with urinary disorders, 63 (41\%) reported at least one fall in the past 3 months, and 9 of these 63 (14\%) patients reported at least one fall while they were going to the bathroom. Severity of LUTSs did not seem to be linked with risk of falls in general but was linked to the specific risk of fall on the way to the bathroom. Severe nocturia was associated with risk of falls during the night. High MSWS12 and TRV scores were associated with falls in the past 3 months on multivariate analysis.

Previous studies have explored the frequency of falls in PwMS, with or without urinary disorders. A systematic review reported a proportion of fallers between $30 \%$ and $63 \%$ in a pool of 2,425 patients[20]. Most falls were reported retrospectively by the patients, over a period from 1 to 12 months depending on the study. Only 3 of 15 studies were prospective. In comparison with large prospective cohorts, we found a slightly lower rate of falls. Thus, in a cohort of 416 PwMS with median EDSS close to 4, Gunn et al. reported $17 \%$ of patients with one fall and 37\% with at least 2 falls in 3 months[2]. In another cohort of 537 PwMS, with a median EDSS similar to the one in our study, $56 \%$ patients reported falls, and $37 \%$ mentioned at least 2 falls during a 3-month period[21]. Most falls were indoors. Regarding falls over the past year, Kalron et al. found $47 \%$ of patients reporting at least 2 falls, close to our rate of $45 \%$ [22]. However, the mean EDSS was lower in their study. Several hypotheses may explain these 
differences: a memory bias in the number of falls reported retrospectively (underestimation) or possible differences in MS typology (duration, course, clinical presentation etc.).

Concerning the impact of LUTS on the risk of falling, our results are not completely consistent with the current literature. In a study of 92 individuals with MS, Sung et al. reported an increased fall frequency for patients with severe urinary disorders versus those with mild troubles on multivariate analysis[6]. However, the severity of urinary disorders was assessed with the EDSS sub-item related urinary continence, which is not precise or specific and could explain our contradictory results. Other studies found a link between risk of falling and urinary incontinence, but not all patients had LUTSs[23], and the results were not adjusted by MS severity or disability[1,5]. In older adults, urinary incontinence is an independent risk factor for falls[4]. A systematic review reported an odds of falling of 1.54 (95\% CI 1.41-1.69) for urge incontinence and $1.11(1.00-1.23)$ for stress incontinence[24]. Age is classically also associated with falls[3]. We did not find an impact of age, probably because our population was young, and severity of MS is the most important factor related to the risk of fall. Finally, some patients had already received treatment for LUTSs, which could reduce urinary symptoms, principally urgency and urge incontinence, and thus, the necessity of precipitation to go to the bathroom. The severity of LUTSs depends on treatment efficacy and this can induce a bias in symptoms' evaluation. However, treatment of LUTSs was not taken into account in the previous studies either.

In our study, nocturia was associated with falls on the way to the bathroom. The impact on falls under any circumstances may have been underestimated owing to lack of power or to the predominant role of gait disorders in our population. One possible hypothesis is that nocturia may affect sleep and induce increased fatigue, which may contribute to the overall risk of falling throughout the day. Our study found an association between nocturia and risk of falling at night 
but not the risk of falling in general, but in older adults, nocturia is a well-established risk factor of falls, also associated with an over-risk of fracture[25].

Our study is the first to specifically assess whether the severity of LUTSs increases the risk of falls in patients with MS and urinary disorders. Our population was more homogenous than in previous studies because all participants had LUTSs, which reinforces our results. Urinary symptoms were for the first time assessed with a validated questionnaire, in addition to a simple declarative response of the presence of urinary incontinence. This is also the first time that the circumstances of falls specifically linked with urinary disorders were studied in this population. Only 9 PwMS reported falls when going to the bathroom and 6 when having a urinary urgency, representing $23 \%$ and 15\%, respectively, of PwMS who reported falls indoor. In older adults, a fall on the way to the bathroom is a classical circumstance, especially during hospitalization, estimated at $20 \%$ to $50 \%$ [15]. In Parkinson's disease, Sakushima et al. showed that $13.8 \%$ of falls occurred on the way to the toilet[26]. They also found an association with urinary urgency and falls. Thus, going to the bathroom is probably a prevalent circumstance of falls indoor, and the risk could be increased in case of frequency and urge urinary incontinence.

We found high MSWS12 and TRV scores associated with falls in the past 3 months. The MSWS12 score is a well-known prognostic factor for the risk of falling [22,27]. This selfreporting questionnaire reports patient perception of gait difficulties. In our study, MSWS12 score was associated with reported falls with an OR close to 1 . However, the association was found for both falls in the past 3 months and in the past year, which strengthens our results.

The TRV test is a new validated test for PwMS[18]. This test assesses quantitatively the time required to reach the bathroom and be ready to void, a complex task, including stand up for a chair, walking, opening a door, and undressing. Several functions are implicated: gait, dexterity, executive functions etc. Because this task is more complex than a Timed up and Go test and because a study showed that the Timed up and Go test failed to predict falls in PwMS[28], we 
decided to use the TRV. The ORs for the 2 factors linked with falls were low, probably because of interactions between them and other factors such as EDSS and fear of falling.

Several limitations exist. First, a number of patients declined participation for different reasons (personal or professional imperatives, tiredness secondary to the appointment, did not want to participate), and we cannot exclude a selection bias. Also, the number and circumstances of falls were declarative. This can induce a memory bias, especially in patients with MS and possible cognitive disorders. Moreover, the number of falls during the night or during urinary urgency being low must be taken into account in the interpretation of our results. Second, the influence of urinary treatment was not evaluated. However, the treatment of LUTSs was not modified in the past 3 months, which limits its impact. Therefore, the number of falls in the past 3 months were primarily studied, limiting the influence of treatment, variability of urinary symptoms and modification in motor impairment (e.g., owing to relapse of MS). Finally, because of the heterogeneity of PwMS in neurological presentation, the detailed data from neurological examinations were not recorded. Thus, we could not assess the risk of falling function of some clinical forms (e.g., pyramidal, cerebellar) and the results of this study must be considered by taking into account these different biases. Other factors may come into play, such as the attentional impact of the need to urinate, which in other populations such as older people or those with Parkinson's disease could be important, so these results cannot be generalized to other populations at risk of falling.

Many perspectives exist. It could be interesting to assess the impact of the treatment of LUTSs on risk of falling with a prospective study. The impact of increased disability should be taken into account with progressive MS or new relapse. The correlation with manometric results, such as the existence of detrusor overactivity on cystometry, could also be assessed. A specific study of individuals with high EDSS score could be interesting, because these people are more at risk of falling, and some treatments can improve LUTSs. To demonstrate a benefit of treatment of 
$\mathrm{OAB}$ symptoms may lead neurologists to detect these symptoms and address the patient to the neuro-urologist. Finally, a prospective study using the TRV test could be interesting to assess its ability to predict falls in MS.

\section{Conclusion}

Severity of LUTSs and urinary incontinence do not seem related to risk of falling in general in PwMS with urinary disorders but are related to increased risk of falling in specific circumstances. Thus, falling on the way to the bathroom is associated with severe OAB symptoms, and severe nocturia increases the risk of falling at night. High MSWS12 and TRV scores were related to falls. Further studies are needed to assess the impact of LUTS treatment on the risk of falling in PwMS.

\section{Legends}

Figure. Flow chart of the study. The exact reasons for refusing to participate were not recorded.

\section{References}

[1] Fritz NE, Eloyan A, Baynes M, Newsome SD, Calabresi PA, Zackowski KM.

Distinguishing among multiple sclerosis fallers, near-fallers and non-fallers. Mult Scler Relat Disord 2018;19:99-104. https://doi.org/10.1016/j.msard.2017.11.019.

[2] Gunn H, Cameron M, Hoang P, Lord S, Shaw S, Freeman J. Relationship Between Physiological and Perceived Fall Risk in People With Multiple Sclerosis: Implications for Assessment and Management. Arch Phys Med Rehabil 2018;99:2022-9. https://doi.org/10.1016/j.apmr.2018.03.019.

[3] Chen P-L, Lin H-Y, Ong JR, Ma H-P. Development of a fall-risk assessment profile for community-dwelling older adults by using the National Health Interview Survey in 
Taiwan. BMC Public Health 2020;20:234. https://doi.org/10.1186/s12889-020-8286-8.

[4] de Rekeneire N, Visser M, Peila R, Nevitt MC, Cauley JA, Tylavsky FA, et al. Is a fall just a fall: correlates of falling in healthy older persons. The Health, Aging and Body Composition Study. J Am Geriatr Soc 2003;51:841-6. https://doi.org/10.1046/j.13652389.2003.51267.x.

[5] Matsuda PN, Shumway-Cook A, Bamer AM, Johnson SL, Amtmann D, Kraft GH. Falls in multiple sclerosis. PM R 2011;3:624-32; quiz 632. https://doi.org/10.1016/j.pmrj.2011.04.015.

[6] Sung J, Shen S, Motl RW, Sosnoff JJ. Bladder function and falls in individuals with multiple sclerosis. Disabil Rehabil 2016;38:2193-7. https://doi.org/10.3109/09638288.2015.1123311.

[7] Gunn H, Creanor S, Haas B, Marsden J, Freeman J. Risk factors for falls in multiple sclerosis: an observational study. Mult Scler Houndmills Basingstoke Engl 2013;19:1913-22. https://doi.org/10.1177/1352458513488233.

[8] de Sèze M, Ruffion A, Denys P, Joseph P-A, Perrouin-Verbe B, GENULF. The neurogenic bladder in multiple sclerosis: review of the literature and proposal of management guidelines. Mult Scler Houndmills Basingstoke Engl 2007;13:915-28. https://doi.org/10.1177/1352458506075651.

[9] Giannantoni A, Scivoletto G, Di Stasi SM, Grasso MG, Vespasiani G, Castellano V. Urological dysfunctions and upper urinary tract involvement in multiple sclerosis patients. Neurourol Urodyn 1998;17:89-98.

[10] Onal B, Siva A, Buldu I, Demirkesen O, Cetinel B. Voiding dysfunction due to multiple sclerosis: a large scale retrospective analysis. Int Braz J Urol Off J Braz Soc Urol 2009;35:326-33. https://doi.org/10.1590/s1677-55382009000300009.

[11] Krhut J, Hradílek P, Zapletalová O. Analysis of the upper urinary tract function in 
multiple sclerosis patients. Acta Neurol Scand 2008;118:115-9.

https://doi.org/10.1111/j.1600-0404.2008.00992.x.

[12] Castel-Lacanal E, Gamé X, Clanet M, Gasq D, De Boissezon X, Guillotreau J, et al. Urinary complications and risk factors in symptomatic multiple sclerosis patients. Study of a cohort of 328 patients. Neurourol Urodyn 2015;34:32-6. https://doi.org/10.1002/nau.22495. [13] Shakir NA, Satyanarayan A, Eastman J, Greenberg BM, Lemack GE. Assessment of Renal Deterioration and Associated Risk Factors in Patients With Multiple Sclerosis. Urology 2019;123:76-80. https://doi.org/10.1016/j.urology.2018.09.014.

[14] Paquin M-H, Duclos C, Lapierre N, Dubreucq L, Morin M, Meunier J, et al. The effects of a strong desire to void on gait for incontinent and continent older communitydwelling women at risk of falls. Neurourol Urodyn 2020;39:642-9.

https://doi.org/10.1002/nau.24234.

[15] Roggeman S, Weiss JP, Van Laecke E, Vande Walle J, Everaert K, Bower WF. The role of lower urinary tract symptoms in fall risk assessment tools in hospitals: a review. F1000Research 2020;9:236. https://doi.org/10.12688/f1000research.21581.1.

[16] Haab F, Richard F, Amarenco G, Coloby P, Arnould B, Benmedjahed K, et al. Comprehensive evaluation of bladder and urethral dysfunction symptoms: development and psychometric validation of the Urinary Symptom Profile (USP) questionnaire. Urology 2008;71:646-56. https://doi.org/10.1016/j.urology.2007.11.100.

[17] Hobart JC, Riazi A, Lamping DL, Fitzpatrick R, Thompson AJ. Measuring the impact of MS on walking ability: the 12-Item MS Walking Scale (MSWS-12). Neurology 2003;60:31-6. https://doi.org/10.1212/wnl.60.1.31.

[18] Hentzen C, Villaumé A, Turmel N, Miget G, Le Breton F, Chesnel C, et al. Time to be Ready to Void: A new tool to assess the time needed to perform micturition for patients with multiple sclerosis. Ann Phys Rehabil Med 2020. https://doi.org/10.1016/j.rehab.2020.01.002. 
[19] van Vliet R, Hoang P, Lord S, Gandevia S, Delbaere K. Falls efficacy scaleinternational: a cross-sectional validation in people with multiple sclerosis. Arch Phys Med Rehabil 2013;94:883-9. https://doi.org/10.1016/j.apmr.2012.10.034.

[20] Giannì C, Prosperini L, Jonsdottir J, Cattaneo D. A systematic review of factors associated with accidental falls in people with multiple sclerosis: a meta-analytic approach. Clin Rehabil 2014;28:704-16. https://doi.org/10.1177/0269215513517575.

[21] Nilsagård Y, Gunn H, Freeman J, Hoang P, Lord S, Mazumder R, et al. Falls in people with MS--an individual data meta-analysis from studies from Australia, Sweden, United Kingdom and the United States. Mult Scler Houndmills Basingstoke Engl 2015;21:92-100. https://doi.org/10.1177/1352458514538884.

[22] Kalron A. The relationship between specific cognitive domains, fear of falling, and falls in people with multiple sclerosis. BioMed Res Int 2014;2014:281760. https://doi.org/10.1155/2014/281760.

[23] Finlayson ML, Peterson EW, Cho CC. Risk factors for falling among people aged 45 to 90 years with multiple sclerosis. Arch Phys Med Rehabil 2006;87:1274-9; quiz 1287. https://doi.org/10.1016/j.apmr.2006.06.002.

[24] Chiarelli PE, Mackenzie LA, Osmotherly PG. Urinary incontinence is associated with an increase in falls: a systematic review. Aust J Physiother 2009;55:89-95. https://doi.org/10.1016/s0004-9514(09)70038-8.

[25] Pesonen JS, Vernooij RWM, Cartwright R, Aoki Y, Agarwal A, Mangera A, et al. The Impact of Nocturia on Falls and Fractures: A Systematic Review and Meta-Analysis. J Urol 2020;203:674-83. https://doi.org/10.1097/JU.0000000000000459.

[26] Sakushima K, Yamazaki S, Fukuma S, Hayashino Y, Yabe I, Fukuhara S, et al. Influence of urinary urgency and other urinary disturbances on falls in Parkinson's disease. J Neurol Sci 2016;360:153-7. https://doi.org/10.1016/j.jns.2015.11.055. 
[27] Tajali S, Shaterzadeh-Yazdi M-J, Negahban H, van Dieën JH, Mehravar M,

Majdinasab N, et al. Predicting falls among patients with multiple sclerosis: Comparison of patient-reported outcomes and performance-based measures of lower extremity functions. Mult Scler Relat Disord 2017;17:69-74. https://doi.org/10.1016/j.msard.2017.06.014.

[28] Quinn G, Comber L, McGuigan C, Galvin R, Coote S. Discriminative ability and clinical utility of the Timed Up and Go (TUG) in identifying falls risk in people with multiple sclerosis: a prospective cohort study. Clin Rehabil 2019;33:317-26.

https://doi.org/10.1177/0269215518793481. 
Table 1. Initial characteristics of participants with multiple sclerosis.

\begin{tabular}{lr}
\hline Age (years), mean (SD) & $50.1(11.5)$ \\
Female & $107(69 \%)$ \\
BMI, mean (SD) & $24.6(5.9)$ \\
EDSS, median [Q1-Q3] & $5[3-6]$ \\
MSWS12, mean (SD) & $65.2(22.5)$ \\
FES-I, mean (SD) & $31.7(10.7)$ \\
TRV total (sec), mean (SD) & $29.7(18.8)$ \\
TRV mobility stage (sec), mean (SD) & $11.1(10.2)$ \\
USP score, mean (SD) & \\
USP stress score (/9) & $1(2)$ \\
USP OAB score (/21) & $6.7(4.7)$ \\
USP voiding dysfunction score (/9) & $5(3.4)$ \\
Warning time (min) & \\
$\leq 1$ & $36(23 \%)$ \\
1-5 & $49(32 \%)$ \\
6-15 & $23(15 \%)$ \\
$>15$ & $46(30 \%)$ \\
Micturition status & \\
Spontaneous void & $94(61 \%)$ \\
CISC & $31(20 \%)$ \\
Mixed & $29(19 \%)$ \\
Urinary incontinence & \\
Indoor & \\
Outdoor & $72(47 \%)$ \\
Nocturia & $88(57 \%)$ \\
0-1 & \\
2 & $89(58 \%)$ \\
$>2$ & $34(22 \%)$ \\
\hline BMI body mass & $31(20 \%)$ \\
\hline
\end{tabular}

BMI, body mass index; EDSS, Expanded Disability Status Scale; MSWS12, 12-Item Multiple Sclerosis Walking Scale; FES-I, Falls Efficacy Scale-International questionnaire; TRV, Time to be Ready to Void; USP, Urinary Symptom Profile; OAB, overactive bladder; CISC, Clean Intermittent Self-Catheterization 
Table 2. Falls and their circumstances in the past 3 months and the past year

\begin{tabular}{lll}
\hline & Past 3 months & Past year \\
\hline Total falls & $91(59 \%)$ & $69(45 \%)$ \\
0 & $20(13 \%)$ & $15(10 \%)$ \\
1 & $43(28 \%)$ & $70(45 \%)$ \\
$\geq 2$ & & \\
Falls outdoors & $107(70 \%)$ & $88(57 \%)$ \\
0 & $22(14 \%)$ & $18(12 \%)$ \\
1 & $25(16 \%)$ & $48(32 \%)$ \\
$\geq 2$ & & \\
Falls indoors & $115(75 \%)$ & $99(64 \%)$ \\
0 & $15(10 \%)$ & $11(7 \%)$ \\
1 & $24(15 \%)$ & $44(29 \%)$ \\
$\geq 2$ & & \\
Falls during the night & $148(96 \%)$ & $148(96 \%)$ \\
0 & $2(1 \%)$ & $2(1 \%)$ \\
1 & $4(3 \%)$ & $4(3 \%)$ \\
$\geq 2$ & & \\
Falls while going to the bathroom & $145(94 \%)$ & $143(93 \%)$ \\
0 & $2(1 \%)$ & $3(2 \%)$ \\
1 & $7(5 \%)$ & $8(5 \%)$ \\
$\geq 2$ & & \\
Falls when having a urinary urgency & $148(96 \%)$ & $147(96 \%)$ \\
0 & $1(1 \%)$ & $2(1 \%)$ \\
1 & $5(3 \%)$ & $5(3 \%)$ \\
$\geq 2$ & & \\
\hline & & \\
\hline
\end{tabular}


Table 3. Association between falls and lower urinary tract symptoms.

\begin{tabular}{|c|c|c|c|c|c|c|c|c|}
\hline & \multicolumn{4}{|l|}{3 months } & \multicolumn{4}{|l|}{1 year } \\
\hline & 0 & 1 & $\geq 2$ & $\mathrm{p}$ & 0 & 1 & $\geq 2$ & $\mathrm{p}$ \\
\hline USP OAB & $6.89(4.62)$ & $6.0(5.2)$ & $6.67(4.66)$ & $0.75^{\mathrm{a}}$ & $6.43(4.58)$ & $6.47(5.58)$ & 7.04 (4.64) & $0.73^{\mathrm{a}}$ \\
\hline USP SUI & $0.96(2.01)$ & $1.35(2.3)$ & $0.95(2.07)$ & $0.73^{\mathrm{a}}$ & $0.84(2.0)$ & $0.93(1.98)$ & $1.19(2.14)$ & $0.61^{\mathrm{a}}$ \\
\hline $\begin{array}{l}\text { USP voiding } \\
\text { dysfunction }\end{array}$ & $4.59(3.45)$ & $4.65(3.45)$ & $5.88(3.19)$ & $0.12^{\mathrm{a}}$ & $4.42(3.44)$ & $4.47(3.58)$ & $5.60(3.28)$ & $0.11^{\mathrm{a}}$ \\
\hline $\begin{array}{l}\text { Urinary incontinence } \\
\text { Yes } \\
\text { No }\end{array}$ & $\begin{array}{l}45(49 \%) \\
46(51 \%)\end{array}$ & $\begin{array}{l}9(45 \%) \\
11(55 \%)\end{array}$ & $\begin{array}{l}18(42 \%) \\
25(58 \%)\end{array}$ & $0.71^{\mathrm{b}}$ & $\begin{array}{l}31(45 \%) \\
38(55 \%)\end{array}$ & $\begin{array}{l}6(40 \%) \\
9(60 \%)\end{array}$ & $\begin{array}{l}35(50 \%) \\
35(50 \%)\end{array}$ & $0.72^{\mathrm{b}}$ \\
\hline Warning time (min) & $23(25 \%)$ & $4(20 \%)$ & $9(21 \%)$ & $0.75^{\mathrm{b}}$ & $15(22 \%)$ & $4(27 \%)$ & $17(24 \%)$ & $0.60^{\mathrm{b}}$ \\
\hline $\begin{array}{l}1-5 \\
6-15 \\
>15\end{array}$ & $\begin{array}{l}30(33 \%) \\
10(11 \%) \\
28(31 \%)\end{array}$ & $\begin{array}{l}5(25 \%) \\
4(20 \%) \\
7(35 \%)\end{array}$ & $\begin{array}{l}14(32 \%) \\
9(21 \%) \\
11(26 \%)\end{array}$ & & $\begin{array}{l}25(36 \%) \\
7(10 \%) \\
22(32 \%)\end{array}$ & $\begin{array}{l}3(20 \%) \\
2(13 \%) \\
6(40 \%)\end{array}$ & $\begin{array}{l}21(30 \%) \\
14(20 \%) \\
18(26 \%)\end{array}$ & \\
\hline $\begin{array}{l}\text { Nocturia } \geq 2 \\
\text { Yes } \\
\text { No }\end{array}$ & $\begin{array}{l}16(18 \%) \\
75(82 \%)\end{array}$ & $\begin{array}{l}4(20 \%) \\
16(80 \%)\end{array}$ & $\begin{array}{l}10(23 \%) \\
33(77 \%)\end{array}$ & $0.74^{\mathrm{b}}$ & $\begin{array}{l}12(17 \%) \\
57(83 \%)\end{array}$ & $\begin{array}{l}4(27 \%) \\
11(73 \%)\end{array}$ & $\begin{array}{l}14(20 \%) \\
56(80 \%)\end{array}$ & $0.71^{b}$ \\
\hline
\end{tabular}

Data are mean (SD) unless indicated.

USP, Urinary Symptom Profile; OAB, Overactive Bladder; SUI, Stress Urinary Incontinence

${ }^{\mathrm{a}}$ ANOVA; ${ }^{\mathrm{b}}$ Fisher exact test 
Table 4. Association between falls and clinical factors.

\begin{tabular}{|c|c|c|c|c|c|c|c|c|}
\hline & \multicolumn{4}{|l|}{3 months } & \multicolumn{4}{|l|}{1 year } \\
\hline & 0 & $\geq 1$ & $\mathrm{p}$ & LR (OR [95\% CI]) & 0 & $\geq 1$ & $\mathrm{p}$ & $\operatorname{LR}(\mathrm{OR}[95 \% \mathrm{CI}])$ \\
\hline Age (years) & $49.3(11.9)$ & $51.2(10.9)$ & $0.30^{\mathrm{a}}$ & ns & $46.9(11.7)$ & $52.6(10.7)$ & $<0.01^{\mathrm{a}}$ & $\mathrm{ns}$ \\
\hline Sex & & & & & & & & \\
\hline Male & $26(29 \%)$ & $21(33 \%)$ & $0.53^{c}$ & ns & $22(32 \%)$ & $25(29 \%)$ & $0.75^{\mathrm{c}}$ & ns \\
\hline Female & $65(71 \%)$ & $42(67 \%)$ & & & $47(68 \%)$ & $60(71 \%)$ & & \\
\hline EDSS & $4.3(1.8)$ & $5.2(1.3)$ & $<0.001^{\mathrm{b}}$ & ns & $4.0(1.7)$ & $5.1(1.4)$ & $<0.001^{\mathrm{b}}$ & ns \\
\hline Fear of falling & & & & & & & & \\
\hline Yes & $52(57 \%)$ & $54(86 \%)$ & $<0.001^{\mathrm{c}}$ & ns & $36(52 \%)$ & $70(82 \%)$ & $<0.0001^{\mathrm{c}}$ & $3.15[1.15-8.31]$ \\
\hline No & $39(43 \%)$ & $9(14 \%)$ & & & $33(48 \%)$ & $15(18 \%)$ & & $\mathrm{p}=0.03$ \\
\hline FES-I & $29.4(11.1)$ & $35.1(9.0)$ & $<0.001^{\mathrm{a}}$ & ns & $28.5(11.9)$ & $34.3(8.8)$ & $<0.001^{\mathrm{a}}$ & ns \\
\hline MSWS12 & $57.1(22.2)$ & $76.9(17.3)$ & $<0.0001^{\mathrm{b}}$ & $\begin{array}{l}1.04[1.01-1.06] \\
p<0.001\end{array}$ & $54.4(23.7)$ & $73.9(17.2)$ & $<0.0001^{\mathrm{b}}$ & $\begin{array}{l}1.03[1.01-1.05] \\
\mathrm{p}<0.01\end{array}$ \\
\hline TRV (sec) & $24.8(13.2)$ & $36.7(23.0)$ & $<0.001^{\mathrm{b}}$ & $\begin{array}{l}1.03[1-1.06] \\
\mathrm{p}=0.03\end{array}$ & $23.8(10.7)$ & $34.5(22.3)$ & $<0.001^{\mathrm{b}}$ & ns \\
\hline Walking device & & & & & & & & \\
\hline Yes & $19(21 \%)$ & $27(43 \%)$ & $0.02^{\mathrm{c}}$ & ns & $12(17 \%)$ & $35(41 \%)$ & $<0.01^{\mathrm{c}}$ & ns \\
\hline No & $72(79 \%)$ & $36(57 \%)$ & & & $57(83 \%)$ & $50(59 \%)$ & & \\
\hline
\end{tabular}

Data are mean (SD) unless indicated.

EDSS, Expanded Disability Status Scale; FES-I, Falls Efficacy Scale-International; MSWS12, 12-Item Multiple Sclerosis Walking Scale; TRV, Time to be Ready to Void

${ }^{\mathrm{a}}$ Student t-test ${ }^{\mathrm{b}}$ Welch two sample t-test; c, chi-squared test; LR, logistic regression (multivariate analysis); OR, odds ratio; 95\% CI, 95\% confidence interval 